\title{
Design Estratégico na área da saúde: proposta metodológica para a Inovação Cultural e Social de associações ligadas a doenças raras
}

\author{
Gustavo Berwanger Bittencourt; \\ Karine de Mello Freire
}

resumo:

A abordagem do Design para as comunidades criativas e a Inovação Social já conta com uma rica trajetória em teoria e projetos ao longo de quase duas décadas. Contudo, uma natural concentração de pesquisa e prática em determinadas áreas sociais deixa em aberto outras, o que apresenta muitas oportunidades. Neste artigo, é introduzida a área da saúde nesse diálogo, especificamente os desafios das associações de pacientes de doenças raras, as quais apresentam características de comunidades criativas e que, entende-se, poderiam beneficiar-se da abordagem do Design Estratégico para Inovação Cultural e Social por sua necessidade de reformular seus modelos organizacionais. Nessa intersecção, é identificada uma lacuna no Design Estratégico: a falta de uma ferramenta para o projeto de estratégias organizacionais que não esteja vinculada à cultura gerencial. Então, é proposta a transformação do Social Innovation Scanner, ferramenta de análise de maturidade de iniciativas de Inovação Social em ferramenta prospectiva e projetual para a formulação de estratégias organizacionais de associações de pacientes de doenças raras. Conclui-se que essa proposta pode ajudar a preencher com coerência teórico-metodológica tal lacuna de métodos e ferramentas para comunidades que desejam inovar em seu modelo organizacional sem precisar recorrer às soluções mais tradicionais disponíveis, especialmente aquelas de lógica mercadológica.

palavras-chave:

Design Estratégico; Inovação Social; Codesign; Doenças Raras; Associativismo 


\section{Introdução}

Há quase duas décadas, a pesquisa e prática em design vem se ocupando do fenômeno das comunidades criativas, pessoas que colaboram para transformar suas vidas de forma inovadora em direção à sustentabilidade (MERONI; FASSI; SIMEONE, 2013). Ao longo dessa trajetória, que inclui, entre outros marcos, a formação da rede de pesquisadores Design for Social Innovation and Sustainability (DESIS), centenas de livros, artigos, dissertações, teses, processos, métodos e ferramentas foram desenvolvidos com o objetivo de potencializar essas comunidades através de diferentes metodologias e abordagens de design. Dentre as utilizadas, o Design Estratégico se destaca no trabalho de pesquisadores ligados a duas escolas de design específicas, o Politecnico di Milano e a Unisinos. O trabalho desenvolvido, orientado ou inspirado por nomes como Ezio Manzini, François Jégou, Anna Meroni, Ione Bentz, Carlo Franzato, Karine Freire e Gustavo Borba, entre outros, estabeleceu os fundamentos da conexão entre o Design Estratégico e a Inovação Social, fundamentos ainda abrangentes e férteis em possibilidades. O tema de uma ocupação mais socialmente justa do espaço urbano através de projetos relacionados a moradia, mobilidade, alimentação e coletivos culturais tem sido a tônica de muitas pesquisas, as quais miram no empoderamento e evolução das comunidades criativas rumo a uma autonomia política, econômica, cultural e social via Design Estratégico. Dentre as áreas com potencial de desenvolvimento de estudos, a área da saúde e, especialmente, o tema das doenças raras, recebeu muito pouca atenção.

E este não é um tema irrelevante. Existem, no Brasil, cerca de 13 milhões de pessoas com doenças raras - aquelas que afetam até $65 \mathrm{em}$ cada 1.000 .000 indivíduos de uma dada população (BRASIL, 2014). Segundo dados da Organização Mundial da Saúde de 2015, entre 6 e 8\% da população mundial tem uma das 8 mil doenças raras conhecidas. Aproximadamente $80 \%$ dessas doenças são disfunções genéticas (FRASÃO, 2018) e, portanto, não tem cura. A maior parte das pessoas que tem uma dessas condições depende inteiramente de um tratamento contínuo, do nascimento até sua morte, ou para sobreviver ou para levar uma vida com um mínimo de qualidade e dignidade. As dificuldades de quem tem uma doença rara, seus cuidadores e suas famílias multiplicam os desafios que pessoas sem doenças raras enfrentam no sistema de saúde brasileiro, seja privado ou público (RUSKY, 2018). Além de tentar fazer valer os princípios de universalidade e integralidade do atendimento em saúde mais básicos propostos pela Constituição, as pessoas envolvidas com doenças raras enfrentam ainda obstáculos como exclusão social associada à doença, falta de tempo e espaço para a vida privada e familiar, falta de apoio doméstico, psicológico e financeiro, além de falta de informação sobre como tratar e lidar com a doença e com seus efeitos subjetivos e sociais (SANTOS LUZ; SILVA; DEMONTIGNY, 2016).

Esse contexto empurra as pessoas afetadas a buscar respostas de maneira fragmentada, mesclando orientações médicas esparsas com a troca de informações em grupos de apoio formados por pares que estão na mesma situação (SANTOS LUZ; SILVA; DEMONTIGNY, 2016). É comum que esses grupos surjam através da articulação direta de mães, pais e cuidadores (MUOTRY, 2007; TUDELA; RAMÍREZ; HENAO, 2018) mesmo quando eles não têm nenhuma habilidade específica de saúde, de gestão ou de comunicação. São simplesmente cidadãs e cidadãos que se deparam com obstáculos aparentemente intransponíveis e que, por amor aos seus ou à sua vida, se sentem impelidos a se associar para, coletivamente, suprir a falta de suporte do poder público ou da iniciativa privada mesmo sem ter todos os recursos materiais e cognitivos para tanto.

Estes grupos muitas vezes acabam se tornando "associações de pacientes de doenças raras", nomenclatura que abriga uma grande variedade de formatos dessas organizações (PEREIRA, 2015), as quais produzem eventos de informação médica, pressionam o legislativo para fazer evoluir as leis, criam e gerenciam websites e fóruns em redes sociais, entre outras atividades. As mães das pessoas com doenças raras costumam desempenhar um papel central nessas associações, transformando-se praticamente em embaixadoras da inclusão em todos os seus aspectos - político, educacional, econômico e social (GRANDELLE, 2018).

Como observado por Barbosa e Portugal (2018), as associações de doenças raras (a partir daqui vamos usar essa terminologia sintética escolhida por eles) costumam seguir um modelo cunhado nos Estados Unidos chamado Modelo Utilitário de Cuidado. Este, cujas origens podem ser traçadas até 
as associações beneficentes americanas surgidas na década de 50, se caracteriza por ser baseado em tratamentos com medicamentos desenvolvidos pela indústria farmacêutica, objetivo que acaba concentrando a maior parte dos recursos humanos e financeiros dos laboratórios, dos centros de pesquisa, do Governo e, por consequência, das associações. Embora a vida ou a qualidade de vida de muitas pessoas com doenças raras dependa de fato desses medicamentos, outros fatores, como a construção de condições para se exercer a cidadania e tratamentos multidisciplinares complementares acabam despotencializados nesse modelo de associação.

Para Barbosa e Portugal (2018), a superação do Modelo Utilitário do Cuidado exige um olhar mais amplo sobre os pacientes e seus possíveis tratamentos, acima de tudo com uma noção mais presente de cidadania e mais profunda de cuidado, não focado exclusivamente em medicamentos. Essa perspectiva implica na construção novas formas de associativismo, cujos objetivos e ações a reflitam a complexidade e profundidade das condições dos pacientes e de todos os atores envolvidos nos tratamentos. Em outras palavras, é preciso mexer no modelo.

Assim sendo, este artigo apresenta uma abordagem metodológica para promover a Inovação Cultural e Social neste tipo de organização. Nas sessões a seguir, serão apresentadas a abordagem do Design Estratégico para Inovação Cultural e Social e a proposta de adaptação de uma ferramenta para a elaboração de estratégias organizacionais.

\section{A abordagem do Design Estratégico para Inovação Cultural e Social}

$\mathrm{O}$ projeto do modelo de uma organização diz respeito à formulação de suas estratégias organizacionais, o que historicamente é proposto e operado por metodologias, métodos, processos e ferramentas da Administração (CASTRO; CARDOSO, 2010). Mas, recentemente, o Design também tem desempenhado um papel de protagonista na formulação desse tipo de estratégia. Freire (2017) defende que o Design está mais bem preparado para a formulação de estratégias organizacionais no contexto socioeconômico contemporâneo, repleto de incertezas e descontinuidades. Tal contexto configura um desafio para o pensamento cartesiano e mecanicista que embasa as ferramentas clássicas da Administração, que ainda assim seguem sendo as mais utilizadas no projeto de estratégias organizacionais.

O Design Estratégico como entendido, com suas devidas nuances, em Mauri (1996), Meroni (2008), Zurlo (2010), Franzato et al. (2015), Franzato e Campelo (2017), Freire (2017) e Manzini (2017), considera a formulação de estratégias organizacionais um projeto coletivo que leva em consideração os múltiplos pontos de vista dos múltiplos atores envolvidos nas múltiplas relações, fluxos e processos que configuram uma organização, levando em conta que essas relações, fluxos e processos definem muito mais uma organização do que seus limites formais jurídicos ou administrativos. Uma proposta que se alinha com a necessidade de inovação no modelo das associações de doenças raras.

A adequação, viabilidade e fertilidade do Design Estratégico como uma metodologia adequada à criação de um novo modelo de associação de doenças raras diz respeito muito à forma como ele lida com a participação dos atores ligados à organização, o que irá refletir mais adiante na definição de seu modelo. Por exemplo, Mauri (1996) descreve como habilidades fundamentais ao projeto coletivo da estratégia a escuta, a gestão de conflitos, a aprendizagem e a qualidade das relações. Para Meroni (2008), diálogos estratégicos ocorrem em todas as fases do projeto no Design Estratégico, da proposição e enquadramento do problema até sua solução, passando pelo contrabriefing, codesign e construção de visões compartilhadas. Franzato et al. (2015, p. 174) colocam como "determinante a capacidade de tornar as estratégias visíveis para todos os atores, de maneira a promover o diálogo e a construção coletiva”.

Em todos esses autores, evidencia-se uma orientação para o diálogo e para a participação coletiva na "configuração da forma, função, valor e sentido de propostas integrais de ações configurantes das sociedades e organizações protagonizadas pelas pessoas" (FRANZATO et al., 2015, p. 175). E isso surge com uma intensidade e amplitude que não encontram paralelo em outras metodologias, especialmente nas que são derivadas da cultura gerencial. Nestas, os pressupostos são, em geral, o controle e a eficiência, duas diretrizes que não raro colidem com a necessidade de diálogo e participação no projeto. 
A noção de "coletivo" no Design Estratégico é peculiar porque realmente inclui como atores fundamentais ao projeto da estratégia aqueles que não estão formalmente ligados à organização, mas que compõem a sua rede de atividades e fluxos (FREIRE, 2014). Na cultura gerencial clássica, decisões estratégicas em geral são tomadas apenas pela alta diretoria, mas o Design Estratégico, segundo as abordagens supracitadas, parte do pressuposto de que a estratégia é resultado das relações e processos que se entrelaçam no ecossistema criativo do qual a organização faz parte. O ecossistema criativo é entendido por Franzato et al. (2015) como o conjunto de atores, relações, recursos e situações criativas que recursivamente produz e é consequência de processos criativos e dispositivos sociotécnicos, e se caracteriza primordialmente pelos fluxos criativos que resultam dessa configuração. Em uma associação de pacientes, esses fluxos transcendem, logo, a delimitação jurídica ou espacial da organização, abarcando todos aqueles atores, recursos, relações e situações criativas na qual ela está implicada. Considera-se, nessa perspectiva, que todo aquele que participe desses fluxos tenha voz no projeto da estratégia sob pena da mesma não construir valor para o ecossistema, acabando por mostrar-se irrelevante.

De outra perspectiva, próxima mas não idêntica, Meroni (2008) propõe que o Design Estratégico pode ser considerado community centered design em oposição ao user centered design não apenas no sentido de um projeto baseado em colaboração e codesign mas também no entendimento de que comunidades reunidas em torno de interesses comuns (entre outros critérios) possibilitam, através de um projeto estruturado para tanto, que os interesses coletivos sejam contemplados expressando e coordenando todos os interesses individuais em vez de anulando alguns e promovendo outros. Ciente das dificuldades inerentes de qualquer projeto coletivo, Meroni, Fassi e Simeone (2013) propõem um roteiro que oferece um caminho estruturado para um projeto de design centrado "na comunidade" e não "no usuário". É a partir dessa perspectiva de coletivo que este artigo entende a pertinência do Design Estratégico para as associações de doenças raras.

Um aspecto do Design Estratégico que une todos os autores que tratam do tema é sua orientação à inovação. Contudo, não qualquer inovação. Especificamente para autores como Manzini, Jégou, Meroni, Franzato, Del Gaudio e Freire, o Design Estratégico tem especial valia quando se necessita gerar uma inovação que vai além do valor mercadológico, a chamada Inovação Social: novas soluções ou novas colaborações que resolvem problemas sociais ao mesmo tempo em que produzem condições que ampliam a capacidade dos cidadãos de, articulados, inovar e resolver seus problemas sociais (MURRAY; CAULIER-GRICE; MULGAN, 2010; MANZINI, 2017).

Porém, embora as oportunidades abundem, a geração de Inovação Social enfrenta uma série de obstáculos. Um deles é o fato dos métodos e processos de inovação tradicionais, oriundos da cultura gerencial, não serem automaticamente transladáveis para a Inovação Social por serem focados na busca de resultados financeiros e em coalizões de estruturas organizacionais excessivamente formais, o que implica em uma ênfase em competição, lucro e crescimento econômico, fatores que não necessariamente são importantes para as comunidades e organizações civis que em geral são protagonistas e público da Inovação Social (MANZINI, 2017). Outro obstáculo, consequência do primeiro, diz respeito ao risco que muitos projetos de Inovação Social correm de não prosperarem por carecerem de métodos ou processos apropriados para nascerem e florescerem (MANZINI, 2017). É para contrapor esses dois obstáculos que se sugere lançar mão do Design Estratégico como compreendido pelos autores já citados.

Resgatando Meroni (2008), o Design Estratégico entra em cena justamente quando é preciso produzir uma ruptura que faz um sistema evoluir em direção à sustentabilidade ambiental e social. Franzato et al. (2015, p. 175) consideram o principal efeito do Design Estratégico "a organização e contínua reorganização das relações e das atividades que são desenvolvidas no ecossistema das empresas públicas e privadas, das ONGs e das demais organizações". Os autores também ressaltam que as inovações socioculturais são o substrato da inovação através do Design Estratégico, o qual, dessa perspectiva, permite "aos coletivos organizados avançarem em seus projetos de qualificação de si e dos contextos de vida". (FRANZATO et al., 2015, p. 176). Para Del Gaudio, Oliveira e Franzato (2014, p. 47-48), a inovação social pode ser uma atividade fim do Design Estratégico quando "entende como as comunidades trabalham e colabora com elas" promovendo "conversas estratégicas" que se tornam "as bases para um processo de aprendizagem que permite a sua evolução".

Portanto, Inovação Social não é compreendida aqui apenas como resultado de um processo de design, mas também motivação e meio. Como motivação, a Inovação Social surge da necessidade das 
pessoas de, coletivamente, adaptarem-se às atuais transformações tecnológicas, econômicas e sóciopolíticas (MANZINI, 2017). Como meio, trata-se das novas formas com que as organizações precisam combinar os recursos que estão à sua disposição ou das novas perspectivas e sentidos que propõem (MANZINI, 2003). Como resultado, é o estabelecimento recorrente de "práticas sustentáveis que criam valor coletivo acima dos interesses individuais". (FEDERIZZI; BORBA, 2015, p. 94).

Portanto, o Design Estratégico, junto do Design de Serviços, é uma disciplina com especial relevância no Design para Inovação Social por conta de sua orientação ao diálogo estratégico e à consequente construção de coalizões que compartilham visões e valores (MANZINI, 2017) e que necessitam formular estratégias organizacionais que transcendam a lógica de competição mercadológica. (FREIRE, 2015). Franzato et al. (2015, p. 159) apoiam-se em Verganti (2012) e Morin (2005) para ampliar o conceito de Inovação Social para Inovação Cultural e Social, levando em consideração "os resultados socioculturais decorrentes da inovação e, também, a construção de novos significados". Falar de cultura, aqui, agrega "os modos de ser, de pensar e de fazer dos grupos sociais" (FRANZATO, et al., 2015, p 162) ao conceito anteriormente citado de Inovação Social, o que permite clarificar seu alcance uma vez que "sociedade é um termo mais abrangente que comporta as realizações culturais, em sentido estrito, e as sociais, em sentido mais largo" (FRANZATO, et al., 2015, p 162).

Contudo, cabe esclarecer esse entendimento não propõe o Design Estratégico para a Inovação Social e Cultural como uma disciplina ou campo singular do Design ou mesmo do Design Estratégico e sim como um ângulo de reflexão e projeto que contemple os conceitos e nuances apresentados. Conforme sugerem Franzato et al (2015) ao situar seu trabalho junto aos ecossistemas criativos,

o interesse do pesquisador em design deveria concentrar-se nas possibilidades de o design afetar a processualidade que é desenvolvida nesses sistemas e nas consequentes e eventuais transformações que ele venha a produzir. (FRANZATO et al, 2015, p. 180)

Ao concentrar-se nessas processualidades, um Design Estratégico para a Inovação Cultural e Social aprofunda a recente, porém plural, intersecção do design e da Inovação Social estabelecendo parâmetros para projetos e pesquisas que tenham a intenção de contribuir para a evolução da sociedade em uma direção mais sustentável, justa e livre levando em consideração toda sua complexidade.

\section{Social Innovation Scanner como ferramenta de formulação de estratégia organizacional}

Apesar de seu rico arcabouço, a teoria e prática do Design Estratégico ainda se encontra ancorada em seus pilares de origem corporativa. Mesmo em trabalhos focados em organizações da sociedade civil de objetivos não comerciais, persistem temas e terminologias ligados ao universo empresarial, como a estratégia baseada em competição, modelos de negócio inspirados em startups, a proposição de sistemas produto-serviço, o branding e assim por diante. O uso de métodos, processos e ferramentas adaptados da cultura gerencial ocorre porque o Design Estratégico voltado à Inovação Cultural e Social ainda carece de um repertório próprio e condizente com suas aspirações. Por exemplo, um grupo de pessoas que esteja em processo de auto-organização para projetar formas inovadoras e sustentáveis de buscar seu bem-estar - como seria o caso das associações de doenças raras - não encontra facilmente ferramentas para projetar a própria organização sem recorrer àquelas derivadas da cultura gerencial.

Propõe-se, nesse artigo, para endereçar essa questão, fazer um olhar diferente sobre o Social Innovation Scanner (Figura 1), uma matriz apresentada em Meroni, Corubolo e Bartolomeo (2017) como parte da metodologia Social Innovation Journey aplicada no projeto Transition ${ }^{1}$.

\footnotetext{
“A Rede Transnacional para Incubação de Inovação Social - TRANSITION - é um projeto de 30 meses que apoia o processo de escalar inovações sociais na Europa desenvolvendo uma rede de incubadoras que aproximam parceiros estabelecidos no campo da inovação social e incubação baseada em inovação. O TRANSITION também produz materiais de aprendizado sobre que metodologias de escala são as mais efetivas em determinadas regiões e qual o nível de impacto dessas metodologias quando transladadas entre regiões." (TRANSITION, 2020, tradução nossa).
} 


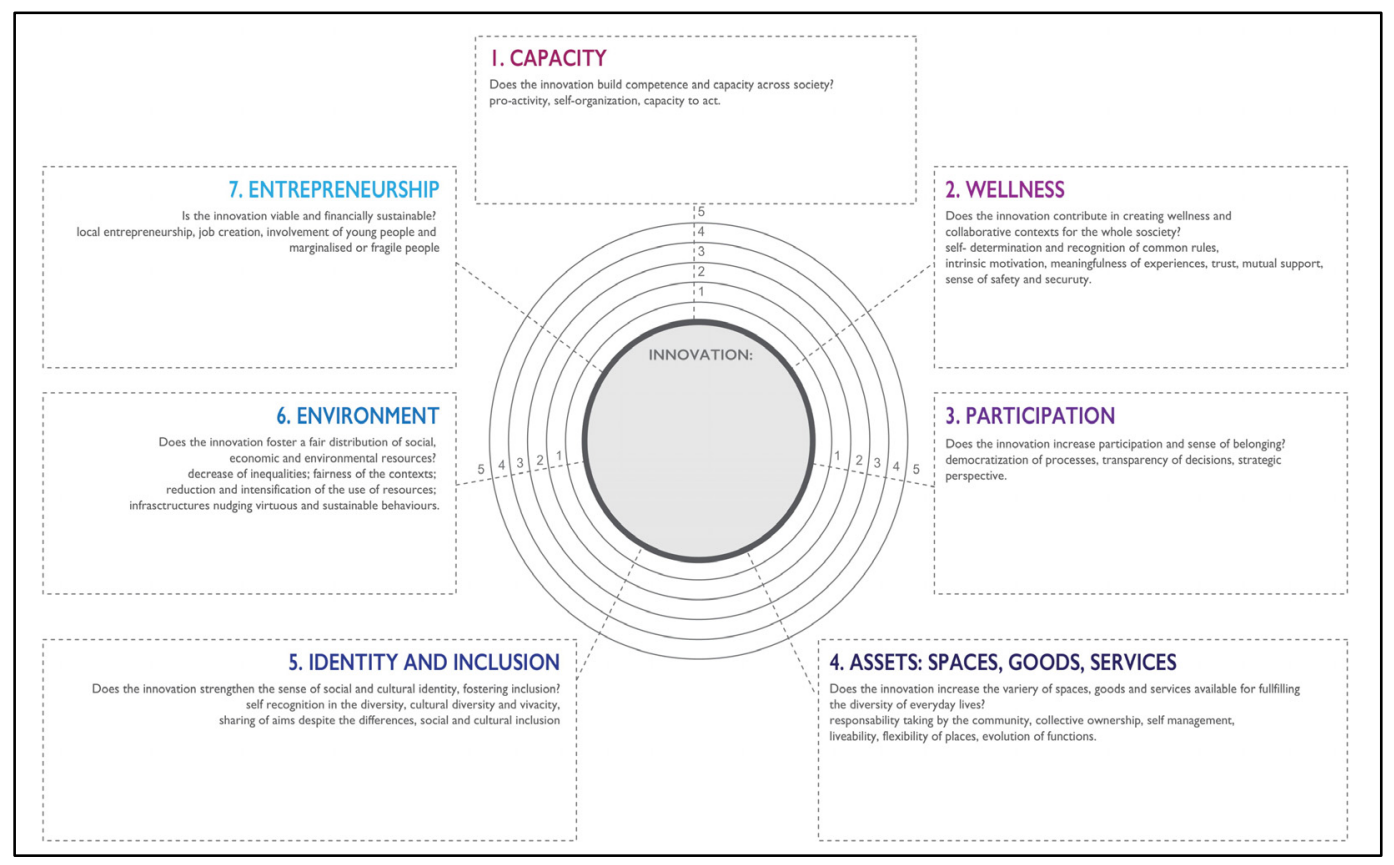

Fonte: Meroni, Corubolo e Bartolomeo, 2017.

O Social Innovation Scanner tem por objetivo evidenciar o potencial de Inovação Social de iniciativas em processo de amadurecimento de acordo com um conjunto de 7 "áreas características e a identificar as ações que geram esses efeitos positivos". (MERONI, CORUBOLO, BARTOLOMEO, 2017, p. 171). As 7 áreas são as seguintes:

- Capacidades: verifica o quanto a inovação engendra habilidades de autonomia e ação na sociedade;

- Bem-estar: verifica o quanto ela colabora para construir bem-estar baseado em significado, confiança e contextos colaborativos;

- Participação: verifica o quanto ela aumenta a participação e o senso de pertencimento;

- Ativos - espaços, produtos e serviços: verifica o quanto ela aumenta a diversidade de ativos para responder à diversidade de necessidades da vida cotidiana;

- Identidade e inclusão: verifica se a inovação fortalece identidades e promove a inclusão, respeitando as diferenças;

- Ambiente: verifica se há distribuição equânime de recursos sociais, econômicos e ambientais;

- Empreendedorismo: verifica a viabilidade e sustentabilidade econômica da inovação observada levando-se em consideração populações vulneráveis e locais.

Embora o Social Innovation Scanner tenha um caráter retrospectivo e analítico, de olhar para iniciativas já em funcionamento e identificar o que pode ser melhorado e escalado, propomos que ele pode também ser adaptado para o uso como ferramenta prospectiva e projetiva para criar o modelo de uma organização voltada à inovação cultural e social - como as associações de doenças raras. A hipótese é que, ao pensar prospectivamente e criativamente cada uma das áreas definidas no Social Innovation Scanner, o resultado é um conjunto de princípios que pode orientar uma organização e não apenas um projeto, ação ou iniciativa isolada - um serviço ou um evento por exemplo.

Para tanto, o Social Innovation Scanner seria modificado de duas maneiras: transformando as questões analíticas de cada área em questões prospectivas e criativas; e unindo as áreas de Participação e Ativos em uma só área chamada de Atividades Participativas, simplificando o processo em um passo e estimulando que as ações criadas nessa área já nasçam participativas, que a participação seja considerada de antemão imbricada em tais soluções. Ao modificarmos o Social Innovation Scanner 
dessa forma, obtemos um roteiro de trabalho com grupos que pode ser utilizado em workshops de codesign para formular, por exemplo, a estratégia organizacional de uma associação de doenças raras. O Quadro 1 apresenta essa nova configuração dos campos do Social Innovation Scanner para ser utilizado como ferramenta prospectiva e projetiva e tarefas de projeto associadas aos campos.

\section{Quadro 1 - Campos do Social Innovation Scanner modificado e suas funções}

\begin{tabular}{|c|c|c|c|}
\hline Campo & Conceito & Tarefa & $\begin{array}{l}\text { Resultado } \\
\text { esperado }\end{array}$ \\
\hline Capacidades & $\begin{array}{l}\text { Entendidas aqui de maneira aberta como habilidades } \\
\text { pessoais e profissionais, conhecimento formal ou } \\
\text { informal, escolar e acadêmico ou derivado de hobbies } \\
\text { e interesses ou mesmo áreas de conhecimento ou } \\
\text { práticas que os participantes desejem desenvolver. É o } \\
\text { que o grupo é capaz de mobilizar conjuntamente para } \\
\text { o projeto. }\end{array}$ & $\begin{array}{l}\text { "Em vez de levantarmos os } \\
\text { problemas que a comunidade } \\
\text { de doenças raras enfrenta, } \\
\text { que tal levantarmos as } \\
\text { capacidades que temos como } \\
\text { grupo?" }\end{array}$ & $\begin{array}{l}\text { Uma síntese das } \\
\text { capacidades } \\
\text { coletivas do grupo. }\end{array}$ \\
\hline Bem-Estar & $\begin{array}{l}\text { Aqui o grupo constrói uma ou mais visões } \\
\text { compartilhadas de bem-estar. Essa especificidade vai } \\
\text { garantir o engajamento das pessoas bem como o } \\
\text { melhor uso de suas Capacidades. Criar uma ou mais } \\
\text { visões de bem-estar antes de criar as ações também } \\
\text { auxilia a evitar problemas de desalinhamento futuros, } \\
\text { promovendo um diálogo estratégico antes de qualquer } \\
\text { iniciativa operacional. }\end{array}$ & $\begin{array}{l}\text { "Com nossas capacidades, } \\
\text { queremos construir uma } \\
\text { situação, uma condição, um } \\
\text { futuro de bem estar para } \\
\text { nossos filhos, pacientes e } \\
\text { alunos. Mas o que queremos } \\
\text { dizer com bem estar? Qual é } \\
\text { nossa visão de bem estar?" }\end{array}$ & $\begin{array}{l}\text { Cenários } \\
\text { representando } \\
\text { bem-estar segundo } \\
\text { o grupo. }\end{array}$ \\
\hline $\begin{array}{l}\text { Atividades } \\
\text { Participativas }\end{array}$ & $\begin{array}{l}\text { Momento de ideação para gerar produtos, serviços, } \\
\text { sistemas produto-serviço, comunicações ou espaços } \\
\text { que utilizam as Capacidades do grupo para que o } \\
\text { grupo e seus beneficiários rumem em direção às suas } \\
\text { visões de Bem-Estar geradas coletivamente. }\end{array}$ & $\begin{array}{l}\text { "Como podemos usar nossas } \\
\text { capacidades para irmos em } \\
\text { direção a esses cenários de } \\
\text { bem estar?" }\end{array}$ & $\begin{array}{l}\text { Ideias consolidadas } \\
\text { para atividades } \\
\text { participativas } \\
\text { relacionando as } \\
\text { capacidades aos } \\
\text { cenários de bem- } \\
\text { estar. }\end{array}$ \\
\hline Inclusão & $\begin{array}{l}\text { Momento para questionar se as Atividades } \\
\text { Participativas permitem a inclusão de pessoas de } \\
\text { diferentes classes sociais, raças, etnias e capacidades } \\
\text { cognitivas, emocionais ou motoras; e levantar que } \\
\text { Capacidades precisam ser adquiridas pelo grupo e que } \\
\text { melhorias precisam ser feitas na visão de Bem-Estar e } \\
\text { nas Atividades Participativas. }\end{array}$ & $\begin{array}{l}\text { "Como garantir que as } \\
\text { atividades do nosso grupo } \\
\text { sejam inclusivas socialmente, } \\
\text { culturalmente e } \\
\text { economicamente?" }\end{array}$ & $\begin{array}{l}\text { Ideias refinadas } \\
\text { pela lente da } \\
\text { inclusão. }\end{array}$ \\
\hline Sustentabilidade & $\begin{array}{l}\text { Da mesma forma, momento para questionar se as } \\
\text { Atividades Participativas são sustentáveis } \\
\text { ambientalmente e socialmente; se promovem um uso } \\
\text { responsável dos recursos naturais, financeiros e } \\
\text { cognitivos de forma que não impeça o } \\
\text { desenvolvimento de outras pessoas no presente e no } \\
\text { futuro. Se isso não ocorre, que Capacidades precisam } \\
\text { ser adquiridas pelo grupo e que melhorias precisam } \\
\text { ser feitas na visão de Bem-Estar e nas Atividades } \\
\text { Participativas? }\end{array}$ & $\begin{array}{l}\text { "Como garantir que as } \\
\text { atividades do nosso grupo } \\
\text { sejam ambientalmente e } \\
\text { socialmente responsáveis?" }\end{array}$ & $\begin{array}{l}\text { Ideias refinadas } \\
\text { pela lente da } \\
\text { sustentabilidade. }\end{array}$ \\
\hline Viabilidade & $\begin{array}{l}\text { Momento para questionar se as Atividades } \\
\text { Participativas são viáveis e sustentáveis } \\
\text { financeiramente no longo prazo; se não, que } \\
\text { Capacidades precisam ser adquiridas pelo grupo e que } \\
\text { melhorias precisam ser feitas na visão de Bem-Estar e } \\
\text { nas Atividades Participativas? }\end{array}$ & $\begin{array}{l}\text { "Como garantir que as } \\
\text { atividades do nosso grupo } \\
\text { sejam viáveis?" }\end{array}$ & $\begin{array}{l}\text { Ideias refinadas } \\
\text { pelo tema da } \\
\text { viabilidade. }\end{array}$ \\
\hline
\end{tabular}


O uso do Social Innovation Scanner modificado se dá como outras ferramentas de design, especialmente no Design Estratégico: através de atividades de codesign que promovem diálogos estratégicos (MERONI, 2003), especialmente em workshops nos quais se pode utilizar as dinâmicas mais adequadas para discutir e gerar conteúdo para cada um dos 6 elementos estratégicos. A ferramenta oferece um roteiro para o uso de um amplo leque de abordagens de diálogos estratégicos e ideação disponíveis, mas de maneira que o resultado não seja apenas um produto, um serviço ou um sistema produto-serviço e sim elementos estratégicos que direcionem a criação e gestão de uma organização.

É necessário, também, compreender em que estágio de desenvolvimento a iniciativa de Inovação Social em questão se encontra e qual é o papel da ação projetual em cada estágio. Uma forma de localizar esse estágio é o método de incubação Social Innovation Journey (Gráfico 2) apresentado em Meroni, Corubolo e Bartolomeo (2017), organizada em 2 ciclos de incubação compreendendo 8 etapas que cobrem em 4 grandes temas.

\section{Figura 2 - Social Innovation Journey.}

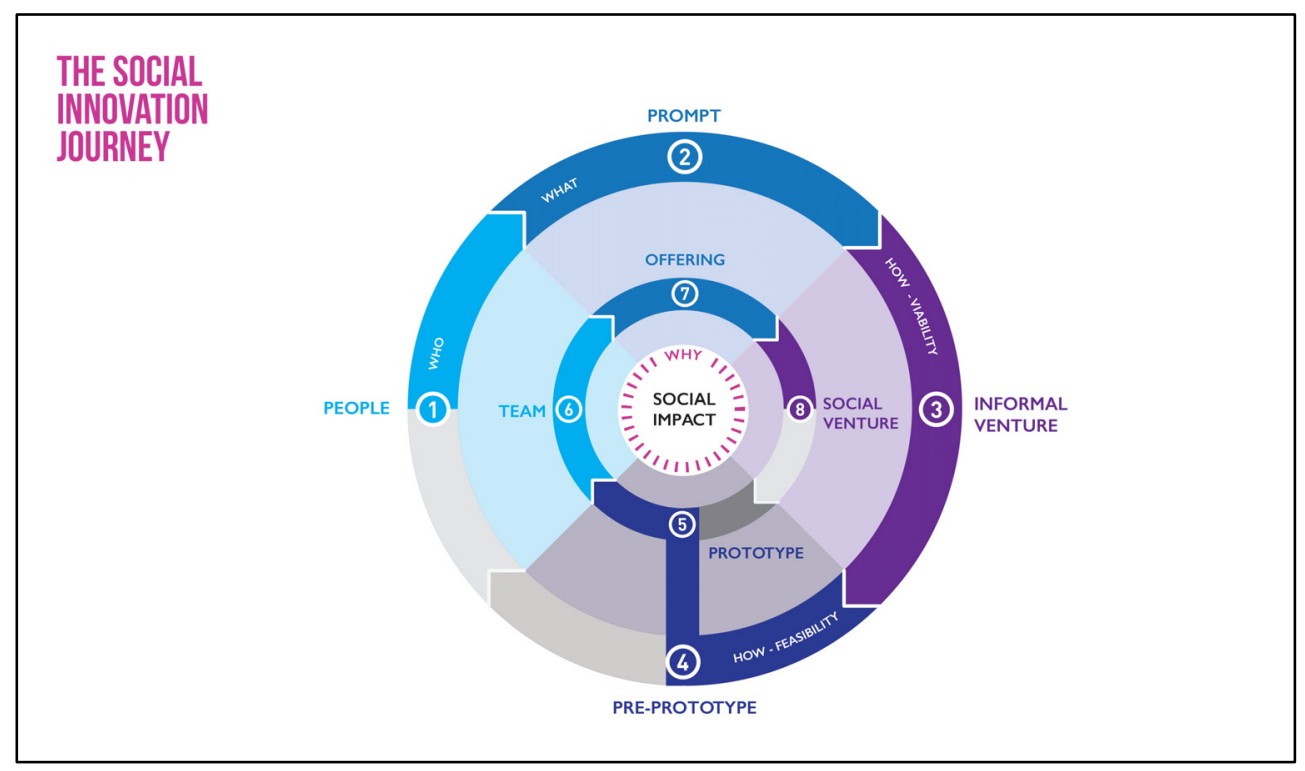

Fonte: Transition, 2020.

A clareza quanto ao estágio de desenvolvimento da iniciativa em questão permite que o designer promova os processos de projeto de acordo com as necessidades do momento e do nível de maturidade do grupo - enquanto grupo e enquanto participantes de um processo de design. Embora Meroni, Corubolo e Bartolomeo (2017, p. 167) destaquem que "a jornada é um processo não-contínuo e nãolinear, com múltiplas iterações possíveis e customizações que dependem das diferentes naturezas dos inovadores sociais", enxergar o projeto pela lente dessa jornada permite maior clareza quanto às iterações e customizações de ferramentas e atividades citadas pelas próprias autoras. Além disso, permite que o grupo e a iniciativa se desenvolvam a um ritmo mais vinculado às suas capacidades $\mathrm{e}$ aspirações coletivas do que às necessidades ou aspirações individuais do designer e dos processos que ele está promovendo ou articulando. O alinhamento do tempo do designer e de grupos sociais com quem ele projeta é uma questão fundamental no codesign como evidenciam Del Gaudio, Oliveira e Franzato (2014).

Considerando-se que o Social Innovation Journey é um método válido e interessante para projetar - e não apenas incubar - iniciativas de Inovação Social dirigidas pelo Design Estratégico, sugerimos que é produtivo o uso do Social Innovation Scanner modificado entre as etapas 2 e 3 (Gráfico 3), no estágio entre os momentos de Prompt e Informal Venture. Nesse estágio, as Pessoas (People) já foram inicialmente mobilizadas (os agentes mais ativos da comunidade, como propõe o Community Centered Design), uma ideia inicial já foi proposta (Prompt) e entra-se no momento de definir a forma de atuação (Informal Venture). 
Figura 3 - Indicação da etapa de aplicação na Social Innovation Journey

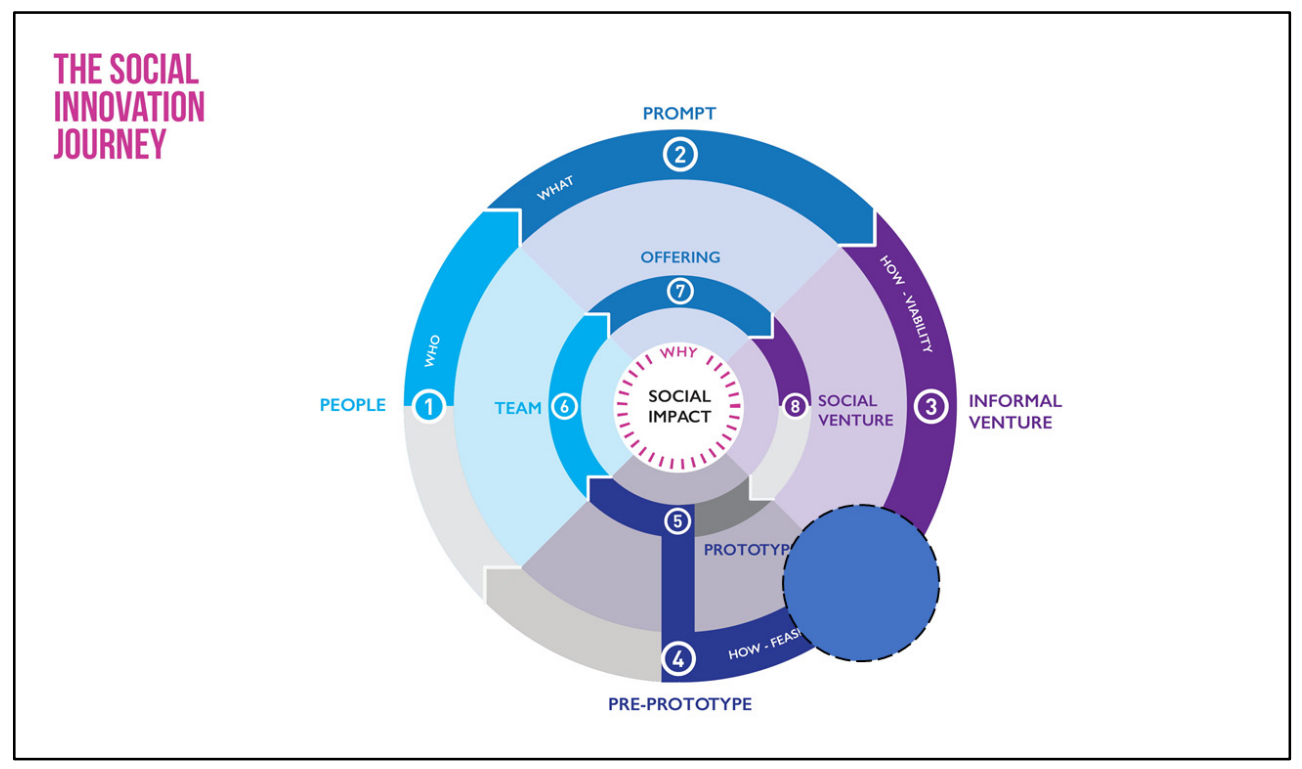

Fonte: Elaborado pelos autores a partir de Transition, 2020.

A visão panorâmica da jornada aqui ajuda a identificar esse momento e a também não parar nesse momento, porque pensar a organização estrategicamente através do Social Innovation Scanner modificado representaria apenas uma etapa da jornada, de forma alguma sua conclusão. Caso o grupo de pessoas envolvidos no projeto siga se encontrando, o designer pode continuar participando do processo de iteração através de atividades de codesign utilizando as ferramentas mais adequadas para cada momento, sempre tendo em vista o caráter de Inovação Social da proposta bem como sua atratividade e viabilidade (MERONI; CORUBOLO; BARTOLOMEO, 2017). O designer, que nesse momento atuou no papel de visionário (identificando um contexto carente de inovação social e criando as condições para o grupo coprojetar essa inovação), pode inclusive assumir outros papeis, como o de fortalecedor (de soluções já encaminhadas), multiplicador (de comportamentos extremos que trariam maior benefício escalados e estruturados) e conector (de relações potenciais) (FEDERIZZI; BORBA, 2015).

O próprio Social Innovation Scanner modificado pode ser utilizado novamente em outros estágios tanto como referência para orientar outros momentos da jornada como para ser atualizada em relação à evolução do grupo. Esse uso estratégico da ferramenta é comparável ao uso, no mercado, do Business Model Canvas, o qual frequentemente é utilizado tanto como ponto de partida para a criação de um modelo de negócios como também de análise e evolução (OSTWERALDER; PIGNEUR, 2011).

Esta proposta como um todo é uma forma humanista de fazer design (Bonsiepe, 2006), humanista ao interpretar as necessidades de grupos sociais e, nesse caso, coprojetar propostas emancipatórias, que implicam na redução de fatores de dominação externa que estejam incidindo sobre esses grupos e impedindo sua liberdade de projetar e desfrutar de novas formas de bem-estar. Em uma era na qual, devido à erosão contínua dos modos tradicionais de viver, um número cada vez maior de pessoas vive em contextos pós-tradicionais e precisa projetar tanto seu dia-a-dia quando sua vida como um todo (MANZINI, 2019), a autonomia e o bem-estar estão cada vez mais ligados às múltiplas condições (individuais e sociais) que permitem esse projetar.

Entendemos que o processo e a ferramenta aqui propostos como meios para a confecção de um ponto na malha democrática imaginada por Manzini (2019). Tal processo e a ferramenta não nascem, portanto, no vácuo, mas alinhados com a noção de que outros pontos podem e devem ser confeccionados por esse e outros recursos de Design, desde que embebidos da intenção de promover não apenas "o próprio ponto" mas a possibilidade da "malha", ou seja que o outro também possa projetar sua vida e sua ideia de bem-estar. E que o faça sem impedir outros ou então, numa visão mais sutil e sofisticada, compreendendo que a separação entre eu e outro (incluindo-se aí o meio ambiente) é ilusória e, logo, prejudicial a todos (SAMTEN, 2019). 


\section{Considerações Finais}

As associações de pacientes com doenças raras enfrentam desafios comuns a muitos outros grupos sociais contemporâneos no mundo todo. Contudo, para grupos como esse, a necessidade de se autoorganizar para inovar no sentido de alcançar seu bem-estar e a capacidade autônoma de reconfigurá-lo quando necessário em um cenário de desigualdade social, degradação do meio ambiente, ruído informacional generalizado e instabilidade política crescentes é mais premente uma vez que suas condições de saúde impõem desafios extras não só às pessoas com doenças raras mas à toda comunidade relacionada. Inovar, nesse cenário, pode ser um desses desafios extras porque as abordagens clássicas de inovação e gestão, que também são as mais conhecidas e disponíveis, têm grandes chances de não oferecer tudo que esses grupos precisam para projetar de forma inovadora e sustentável rumo a seu bem-estar.

Nossa proposta de modificação do Social Innovation Scanner, ancorada no Design Estratégico para Inovação Cultural e Social, se caracteriza por uma preocupação com a construção ou potencialização da autonomia dos participantes do projeto, o que é ressaltado por colocar como primeira etapa o levantamento das Capacidades do grupo. Em seguida, é incentivado o pensamento crítico, imaginativo e estratégico ao convidar o grupo para criar e alinhar sua visão de Bem-Estar para só então entrar no momento mais tático de ideação das Atividades Participativas. Em seguida, são sequenciados três momentos de refinamento do projeto introduzindo os olhares da Inclusão, Sustentabilidade e Viabilidade - que não apenas resgatam o aspecto social do projeto como também reforçam seu caráter estratégico.

Nossa hipótese é que o uso dessa ferramenta dentro de um processo gerado e executado por uma coalizão de design, na qual designers e não-designers colaboram horizontalmente para gerar valor compartilhado (MANZINI, 2017), permitiria às pessoas com doenças raras, seus familiares, médicos, terapeutas, professores e amigos, todos juntos, avançar estrategicamente. Isso significa superar o Modelo Utilitário de Cuidado (BARBOSA E PORTUGAL, 2018), criando novos modelos associativos que, além de atividades tradicionais como advocacy e pressão legislativa em busca de medicamentos, possam promover novas visões de bem-estar baseados no protagonismo, na autonomia, na inclusão e na sustentabilidade em todas as suas dimensões.

\section{Strategic Design in Healthcare: a methodological approach to Cultural and Social Innovation for rare diseases patients' organizations}

Abstract: The Design approach on creative communities and Social Innovation already has a rich trajectory in theory and projects built during the last two decades. However, a natural concentration of research and practice in certain social areas leaves others open. This situation presents many opportunities. In this article, the healthcare area is brought to this dialogue, more specifically the challenges of rare disease patients' organizations, which have characteristics of creative communities and which, it's our understanding, could benefit using the Strategic Design for Cultural and Social Innovation approach when dealing with the need to reformulate its organizational models. At this intersection, a gap in Strategic Design is identified: the lack of a tool for the design of organizational strategies that is not linked to the management culture. Therefore, it is proposed here to transform the Social Innovation Scanner, a tool for analyzing the maturity of Social Innovation initiatives into a prospective and design tool for the formulation of organizational strategies for rare disease patients' organizations. It is concluded that this proposal can help to fill this gap with specific methods and tools for communities that wish to innovate in their organizational model without having to resort to the most traditional solutions available, especially those born out of the market logic. 


\section{Referências bibliográficas}

BARBOSA, Rogério Lima; PORTUGAL, Sílvia. $O$ associativismo faz bem à saúde? $\mathrm{O}$ caso das doenças raras. Ciência \& saúde coletiva. Rio de Janeiro, v. 23, n. 2, p. 417-430, fev. 2018. Disponível em: http://www.scielo.br/scielo.php?script=sci_arttext\&pid=S141381232018000200417\&lng=en\&nrm=iso. Acesso em: 24 mar 2019.

BONSIEPE, Gui. Design and democracy. Design Issues, Cambridge, v. 22, n. 2, p. 27-34, 2006. Disponível em: https://www.mitpressjournals.org/doi/pdf/10.1162/desi.2006.22.2.27. Acesso em: 26 fev. 2020.

BRASIL. Ministério da Saúde. Portaria n 199, 30 de janeiro de 2014. Institui a Política Nacional de Atenção Integral às Pessoas com Doenças Raras, aprova as Diretrizes para Atenção Integral às Pessoas com Doenças Raras no âmbito do Sistema Único de Saúde (SUS) e institui incentivos financeiros de custeio. Brasília, DF: Ministério da Saúde, 2014. Disponível em: http://bvsms.saude.gov.br/bvs/saudelegis/gm/2014/prt0199_30_01_2014.html. Acesso em: 24 mar. 2019.

CASTRO, Maria Luiza Almeida Cunha de; CARDOSO, Juliana. Estratégia e design: construção das abordagens contemporâneas. Strategic design research journal, São Leopoldo, v. 3, n. 3, p. 6975, 2010. Disponível em: http://revistas.unisinos.br/index.php/sdrj/article/view/4789. Acesso em: 26 fev. 2020.

DEL GAUDIO, Chiara; OLIVEIRA, Alfredo Jefferson; FRANZATO, Carlo. O tempo no design participativo. In: P\&D, 11., 2014, Gramado. Anais... São Paulo: Blücher, 2014.

DESIGN FOR SOCIAL INNOVATION AND SUSTENTABILITY (DESIS). 2016. Disponível em: https://www.desisnetwork.org/. Acesso em: 22 de jan. 2020.

FEDERIZZI, Carla Link; BORBA, Gustavo Severo de. Design para inovação social no âmbito da cidade: da teoria a práticas no Estado de São Paulo. In: FREIRE, Karine de Mello (org.). Design estratégico para a inovação cultural e social. São Paulo: Kazuá, 2015. p. 83-116.

FRANZATO, Carlo; CAMPELO, Filipe. Special issue: strategic design research journal tenth volume. Strategic design research journal, São Leopoldo, v. 10, n. 2, p. 89-90, 2017. Disponível em: http://revistas.unisinos.br/index.php/sdrj/article/view/14619. Acesso em: 22 fev. 2020.

FRANZATO, Carlo et al. Inovação cultural e social: design estratégico e ecossistemas criativos. In: FREIRE, Karine de Mello (org.). Design estratégico para a inovação social e cultural. São Paulo: Kazuá, 2015. p. 157-182.

FRASÃO, Gustavo. Ministério da Saúde lança protocolos para 12 doenças raras. Brasília: Ministério da Saúde, 2018. Disponível em: http://portalms.saude.gov.br/noticias/sas/18133-ministerio-dasaude-lancaprotocolos-clinicos-para-12-doencas-raras. Acesso em: 24 mar. 2019.

FREIRE, Karine. Design estratégico: origens e desdobramentos. In: P\&D, 11., 2014, Gramado. Anais... São Paulo: Blücher, 2014. p. 2815-2829.

FREIRE, Karine de Mello. Design estratégico para inovação social. In: FREIRE, Karine de Mello (org.). Design estratégico para a inovação social e cultural. São Paulo: Kazuá, 2015. p.13-41.

FREIRE, Karine de Mello. From strategic planning to the designing of strategies: a change in favor of strategic design. Strategic design research journal, São Leopoldo, v. 10, n. 2, p. 91-96, 2017. Disponível em: http://revistas.unisinos.br/index.php/sdrj/article/view/sdrj.2017.102.01. Acesso em: 26 fev. 2020.

GRANDELLE, Renato. Mães conquistam espaço e atenção para síndromes raras, por causa de seus filhos. 0 globo, Rio de Janeiro, 7 de maio de 2018. Disponível em:

https://blogs.oglobo.globo.com/to-dentro/post/maes-conquistam-espaco-e-atencao-para-sindromesraras-por-causa-de-seus-filhos.html. Acesso em: 24 mar. 2019.

MANZINI, Ezio. Scenarios of sustainable wellbeing. Design philosophy papers, [S.I.], v. 1, n. 1, p. 5-21, 2003. Disponível em: 
https://changedesign.org/Resources/Manzini/Manuscripts/ManziniScenarios.pdf. Acesso em: 22 fev. 2020.

MANZINI, Ezio. Design culture and dialogic design. Design issues, Cambridge, v. 32, n. 1, p. 52-59, 2016. Disponível em: https://www.mitpressjournals.org/doi/pdf/10.1162/DESI_a_00364. Acesso em: 20 fev. 2020.

\section{MANZINI, Ezio. Design quando todos fazem design: uma introdução ao design para a} inovação social. São Leopoldo: Unisinos, 2017.

MANZINI Ezio. Politics of the everyday. London: Bloomsbury, 2019.

MAURI, Francesco. Progettare progettando strategia. Milano: Masson S.p.A., 1996.

MERONI, Anna; CORUBOLO, Marta; BARTOLOMEU, Matteo. The social innovation journey: emerging challenges in service design for the incubation of social innovation. In: SANGIORGI, Daniela;

PRENDIVILLE, Alison (ed.). Designing for service: key issues and new directions. Londres: Bloomsbury, 2017. p. 163-181.

MERONI, Anna. Depicting solutions: tools and techniques for describing services. In: MANZINI, Ezio; JÉGOU, François (org.). Sustainable everyday: scenarios of urban life. Milano: Edizioni Ambiente, 2003. p. 235-239.

MERONI, Anna; FASSI, Davide; SIMEONE, Giulia. Design for Social Innovation as a form of design activism: an action format. In: SOCIAL FRONTIERS: the next edge of social innovation research conference proceedings. London: Nesta, 2013. Disponível em:

https://www.researchgate.net/publication/263016635_Design_for_Social_Innovation_as_a_form_of_D esign_Activism_An_action_format. Acesso em: 24 mar. 2019.

MERONI, Anna. Strategic design: where are we now: reflection around the foundations of a recent discipline. Strategic design research journal, São Leopoldo, v. 1, n. 1, p. 31-38, 2008. Disponível em: http://revistas.unisinos.br/index.php/sdrj/article/view/5567. Acesso em: 20 fev. 2020.

MORIN, Edgar. Introdução ao pensamento complexo. Porto Alegre: Sulina, 2005.

MUOTRY, Alysson. Associações de pais e pacientes. G1, São Paulo, 7 de setembro de 2007. Disponível em: http://g1.globo.com/platb/espiral/2007/09/07/associacoes-de-pais-e-pacientes/. Acesso em: 24 mar. 2019.

MURRAY, Robin; CAULIER-GRICE, Julie; MULGAN, Geoff. The open book of social innovation. Londres: The Young Foundation \& Nesta, 2010.

OSTERWALDER, Alexander; PIGNEUR, Yves. Business model generation. inovação em modelos de negócios. Rio de Janeiro: Alta Books, 2011.

PEREIRA, Camila Claudiano Quina Pereira. Sobre a participação das associações de pacientes na construção do conhecimento sobre saúde: o caso das doenças raras. 2015. 152f. Tese (Doutorado em Psicologia Social) - Programa de Estudos Pós-Graduados em Psicologia: Psicologia Social, Pontifícia Universidade Católica de São Paulo, São Paulo, 2015. Disponível em:

https://tede2.pucsp.br/bitstream/handle/17094/1/Camila\%20Claudiano\%20Quina\%20Pereira.pdf. Acesso em: 20 mar. 2019.

RUSKY, Renata. Como conviver com doenças raras: pacientes revelam suas lutas. Correio Braziliense, [Brasília], 29 de abril de 2018. Disponível em:

https://www.correiobraziliense.com.br/app/noticia/revista/2018/04/29/interna_revista_correio,676791 /como-conviver-com-doencas-raras-pacientes-revelam-suas lutas.shtml. Acesso em: 24 mar. 2019.

SAMTEN, Padma. Relações e redes. Viamão: Ação Paramita, 2019.

SANTOS LUZ, Geisa dos; SILVA, Mara Regina Santos da; DEMONTIGNY, Francine. Priority needs referred by families of rare disease patients. Texto \& Contexto: enfermagem, Florianópolis, v. 25, n. 4, nov. 2016. Disponível em:

http://www.scielo.br/scielo.php?script=sci_arttext\&pid=S010407072016000400311\&lng=en\&nrm=iso. Acesso em: 24 mar. 2019. 
TUDELA, Juan Carrión; RAMÍREZ, Gloria Pino; HENAO, Alicia Males. Do movimiento asociativo de las enfermedades raras em Iberoamérica. Murcia: Alianza Iberoamericana de Enfermedades Raras o Poco Frecuentes, 2018.

VERGANTI, Roberto. Design-Driven Innovation. São Paulo: Canal Certo, 2012.

ZURLO, F. Design strategico. Roma: Enciclopedia Treccani, 2010. v. 4. Disponível em: http://www.treccani.it/enciclopedia/design-strategico_\%28XXI-Secolo\%29/. Acesso em: 24 mar. 2019. 